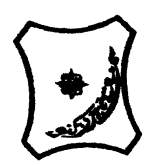

Bayero Journal of Pure and Applied Sciences, 10(2): 226 - 232

Received: October, 2017

Accepted: December, 2017

ISSN $2006-6996$

\title{
GEOLOGICAL INFLUENCE ON THE TERRESTRIAL GAMMA RADIATION DOSE RATE IN JOS PLATEAU, NIGERIA
}

\author{
${ }^{1}$ Habu Tela Abba and ${ }^{{ }^{1}}$ Hassan Abdulsalam \\ ${ }^{1}$ Department of Physics, Yobe State University, Damaturu, Nigeria \\ *Corresponding author: ahassanabdulsalam@gmail.com, 08068061599
}

\begin{abstract}
Natural environmental terrestrial gamma radiation dose (TGRD) rate measurements have been carried out across the geological formations of Jos Plateau, Nigeria. External gamma radiation dose rates ranged between 11 and 714 nGy $h^{-1}$ with a mean value of 204 nGy $h^{-1}$. Relationship between TGRD levels and geological type was determined. Statistical comparative method one way analysis of variance (ANOVA) was used to compare the TGRD means for the various types. The statistical results revealed in some instances, significant differences among the mean values of TGRD rates for the different underlying geological structures. Annual effective dose and collective effective dose for the general public due to exposure to terrestrial gamma radiation were estimated at 0.25 $m S v y^{-1}$ and $1.20 \times 10^{2} \mathrm{mSv}^{-1}$, respectively. Isodose map for exposure rate due to TGRD wasplotted using ArcGIS software. The results will serve as database for natural background radiation for the country.
\end{abstract}

Keywords: Natural radiation; Terrestrial gamma radiation dose (TGRD); geological type; Analysis of variance (ANOVA)

INTRODUCTION

Human being is continuously and unavoidably exposed from his birth to death to background radiations from natural sources. Gamma radiation from natural sources has being the largest contributor to the external radiation dose to population worldwide (Jibiri, 2001). Exposure to natural gamma radiation in the environment is from cosmic sources and significantly from primordial terrestrial radionuclides ${ }^{226} \mathrm{Ra},{ }^{232} \mathrm{Th}$ and ${ }^{40} \mathrm{~K}$ which exist in varying concentrations within the earth crust (UNSCEAR, 2000). Their concentration in soils strongly depend on the geological structure of a particular region and their concentration has reported to be higher in granitic types of igneous rocks due the presence of substantial amount of accessory radioactive mineral monazite and zircon in igneous rocks compared to sedimentary and low-grade metamorphic rocks (UNSCEAR, 2008).

Environmental natural background information is necessary in assessing any possible changes in the level of background radiation due to local and international releases from nuclear practice. The importance of data base on natural radiation levels was recently rose in Japan when the unprecedented nuclear accident occurred on 11 March, 2011. Therefore, the present study is aimed at determining the extent geological types in Jos Plateau influenced TGRD rates levels.

\section{MATERIALS AND METHODS}

Area of study

Jos Plateau lies between the geographical location of latitudes $8^{\circ} 33^{\prime \prime}-10^{\circ} 24^{\prime \prime} N$ Longitudes $8^{\circ} 20^{\prime \prime}-9^{\circ} 30^{\prime \prime} E$ in the north-central part of Nigeria (Hassan et al., 2015). The climate is the wet and dry type classified as tropical rainy climate by Koppen (Olowolafe, 2008). The study area consist of nine local government areas (LGAs) with a total population of $1,933,505$ (NPC, 2006) and a land mass of $15,038 \mathrm{~km}^{2}$.

Geological structure of the area

Jos plateau is composed of eight geological types classified under three geological groups namely; the basement complex, younger granites and volcanic rocks as executively studied by Falconer (1921). About $50 \%$ of Jos Plateau is underlain by basement complexes such as migmatite-gneiss-quartzite, in some places the basement complex is intruded by Precambrian to the late Paleozoic Pan-African granite (Older Granite), diorite, charnockite. An intrusion of younger granites is also associated with the basement complex. Volcanic rocks such as basalts and rhyolites are found to overlie or cut across the younger granites formation as well as the basement complex. The volcanic rocks are believed to be formed during the Tertiary period (Older basalts) and Quaternary period (Newer basalts) (Macleod, Turner, \& Wright, 1971).The geological types and their composition are as follows: Basement complex (G1): Composed of metamorphosed Pre-Cambrian sedimentary and volcanic rocks, Fine and medium grained Biotite (G2): It is composed of dark phyllosilicate mica mineral and medium-grade metamorphic rock, Older granites (G3): Mostly composed of felsic acidic intrusive igneous rock, Rhyolite (G4): Composed of finegrained porphyritic igneous rock dominated by phenocrysts (60\%) and quartz (40\%) in groundmass, Older basalt of Jos (G5): 
Composed of fine-grained igneous rocks, New basalts (G6): Composed of cones and lavas flows basaltic scoria (clay) and pyroclastics overlaid by a thick cap of lateritic ironstone, Sandstone, sandy clay and shale (G7): Composed of medium to coarse grained sandstone covered by sediments and Younger granites (G8): Composed of coarse grained Biotite microgranitesand some basic rocks. Digital map of the geological formations of Jos Plateau is shown in Figure 1.

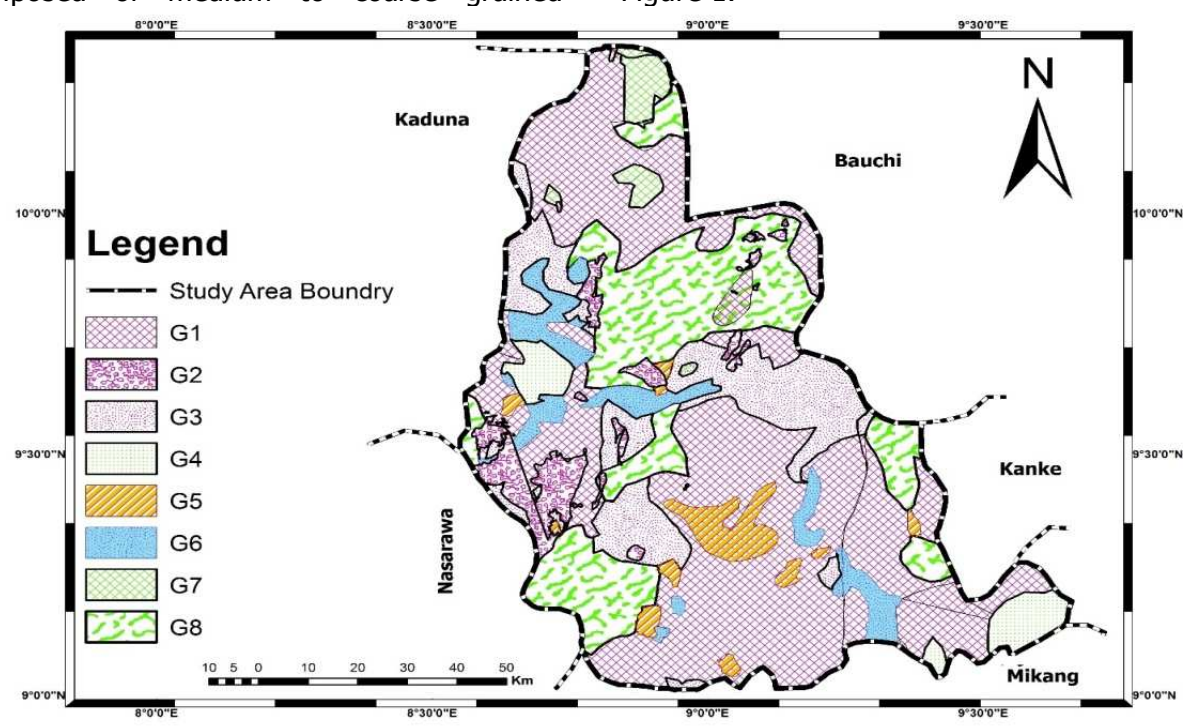

Figure 1. Geological types of the study area.

\section{MEASUREMENT OF TGRD RATES}

Terrestrial gamma radiation dose rates in air were measured $1 \mathrm{~m}$ above the ground surface at 245 different locations using a portable handheld $\mathrm{NaI}(\mathrm{TI})$ survey meter. The instrument used has an accuracy of $\pm 10 \mathrm{nGy} \mathrm{h}{ }^{-1}$ manufactured by Ludlum Corporation with model number 19 (Ludlum Measurement, 1993). Measurements were conducted across all the geological types and coordinates of measurement points were recorded with the aid of Geographical Positioning System (GPS). The location of the measurement is depicted in Figure 2. Dose rate readings were recorded in $\mathrm{R} \mathrm{h}^{-1}$ and subsequently converted to $\mathrm{nGy} \mathrm{h} \mathrm{h}^{-1}$ using a conversion factor ( $1 \mathrm{R} \mathrm{h}^{-}$ between the energy range of 0.08 and $1.2 \mathrm{MeV}$ make excellent to cover the majority of the gamma radiation from natural sources (Knoll, 2010). The survey meter was calibrated at high dose at the Malaysian Nuclear Agency, which is recognised by the IAEA as a Secondary Standard Dosimetry Laboratory. To know the actual terrestrial gamma dose rate at all locations based on field survey, it should be noted that all the data set uniformly include the dose rate of $30 \mathrm{nGy} \mathrm{h} \mathrm{h}^{-1}\left(3.4 \mathrm{R} \mathrm{h}^{-1}\right)$ due to ionizing component of cosmic radiations generated from the outer space (Masahide Furukawa \& Shingaki, 2012). Therefore, terrestrial gamma radiation dose rates are derived by taken off $30 \mathrm{nGy} \mathrm{h} \mathrm{h}^{-1}$ from the each measured value.

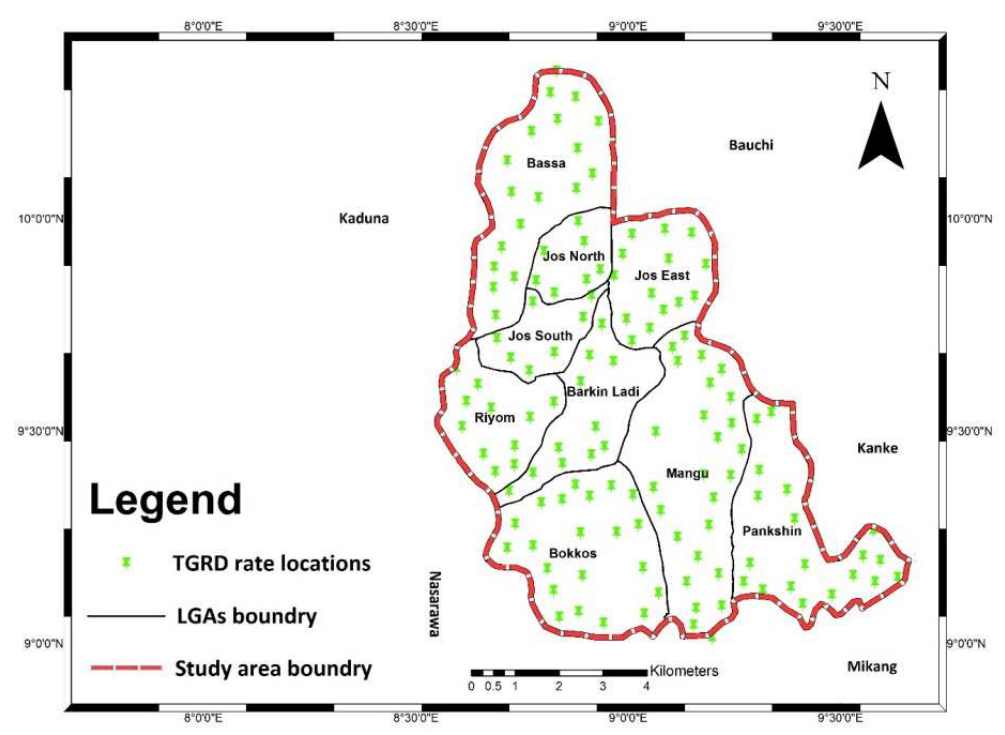

Figure 2. TGRD measurement locations 


\section{RESULTS AND DISCUSSION}

Terrestrial gamma radiation dose rates ranged between 11 and $714 \mathrm{nGy} \mathrm{h}^{-1}$ with overall mean of 204 $n G y h^{-1}$. The mean value is found to be three times fold the world reference average value of $59 \mathrm{nGy} \mathrm{h}^{-}$
${ }^{1}$ (UNSCEAR, 2008). Fifty percent (50\%) of the measured TGRD rate ranged between 166 and 244 $n G y h^{-1}$. The readings were transformed to natural logarithm to fit the normal distribution curve as shown in Figure 3.

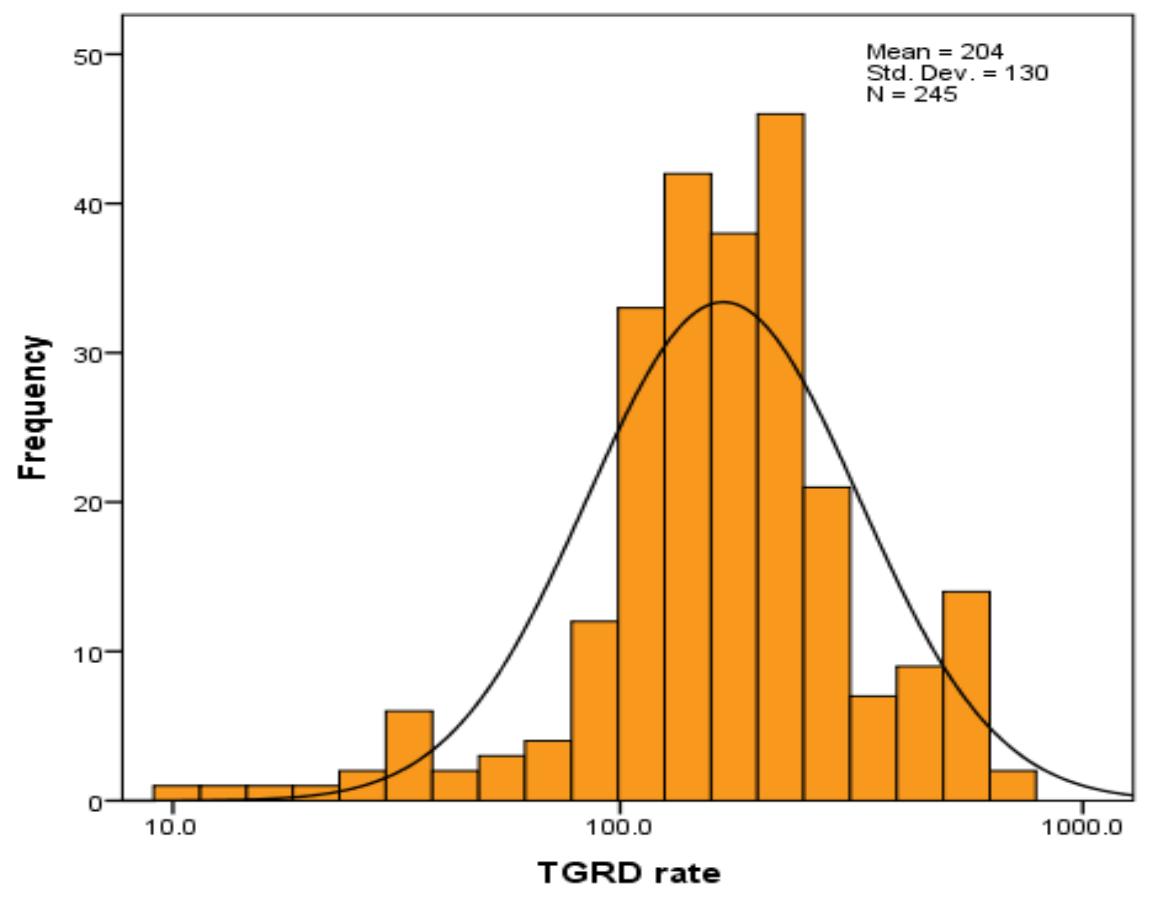

Figure 3. Frequency distribution of In(TGRD rate).

Table 1 presents the summary of descriptive statistical analysis for each geological type generated by Statistical Package Social Science (SPSS) software. For each geological feature, the standard deviation is less than the mean value. Therefore, the statistics indicate high degree of uniformity in the distribution of the dose rates for each geological feature (Ravisankar et al., 2015). The highest mean dose rate $289 \mathrm{nGy} \mathrm{h}^{-1}$ was observed with geological type younger granite, this is in agreement with similar studies conducted by M. Furukawa (1993) and Lai, Hu, Minato, Kodaira, and Tan (1999) whom reported highest dose rate over granitic regions in Japan. The lowest mean dose rate $145 \mathrm{nGy} \mathrm{h}^{-1}$ is associated with sandstone, clay and shale geological type. This geological type is formed from sedimentary rocks which has been reported to present low dose rates (Tzortzis, Svoukis, \& Tsertos, 2004).

Table 1: Descriptive statistics of dose rate for each geological formation.

\begin{tabular}{|c|c|c|c|c|c|c|c|c|}
\hline \multirow[t]{2}{*}{ Statistic } & \multicolumn{8}{|c|}{ Geological type } \\
\hline & G1 & G2 & G3 & G4 & G5 & G6 & G7 & G8 \\
\hline Mean & 240 & 155 & 221 & 207 & 167 & 171 & 145 & 289 \\
\hline Std. error & 19 & 13 & 19 & 24 & 13 & 26 & 12 & 32 \\
\hline Std. Dev. & 145 & 62 & 124 & 104 & 63 & 165 & 55 & 143 \\
\hline Median & 201 & 131 & 182 & 165 & 15 & 129 & 152 & 299 \\
\hline Minimum & 37 & 81 & 72 & 102 & 59 & 11 & 39 & 119 \\
\hline Maximum & 713 & 297 & 57 & 518 & 288 & 714 & 241 & 551 \\
\hline $\begin{array}{l}95 \% \text { conf. interval of } \\
\text { mean }\end{array}$ & $202-277$ & $129-181$ & $181-261$ & $157-257$ & $139-195$ & $117-224$ & $120-170$ & $221-356$ \\
\hline Skewness & 1.5 & 0.63 & 1.33 & 1.82 & 0.05 & 1.61 & 0.12 & 0.36 \\
\hline Error of skewness & 0.31 & 0.47 & 0.36 & 0.52 & 0.49 & 0.38 & 0.50 & 0.51 \\
\hline Kurtosis & 1.64 & -0.74 & 1.28 & 3.69 & -0.75 & 2.57 & -0.35 & -1.05 \\
\hline Error of kurtosis & 0.60 & 0.93 & 0.74 & 1.01 & 0.95 & 0.74 & 0.97 & 0.99 \\
\hline Harmonic mean & 173 & 134 & 121 & 174 & 140 & 57 & 119 & 223 \\
\hline Geometric mean & 204 & 144 & 193 & 188 & 154 & 104 & 133 & 254 \\
\hline
\end{tabular}


In summary, box plot is used to fully describe the distribution of TGRD rates for each geological type based on minimum, first quartile, median, third quartile and maximum as shown in Figure 4. In each box plot, the box represent $50 \%$ of the dose rate distribution for each geological formation, while the solid line across each box represent the arithmetic median of the dose rates. The first quartile (25\%) and the third quartile $(75 \%)$ of dose rate distribution for each geology are represented by two vertical lines (whiskers) extending from the box. The minimum and maximum values for each geology are represented by two horizontal lines beyond the whiskers. The value of TGRD that are extreme and beyond the extreme (outliers) are represented by $*$ and 0 , respectively.

TGRD rates distributions are skewed positively for G7 and G8 while negative skewness is observed with G2, G3, G4 and G5 geological types. The distributions are observed to be symmetrical for geological types G1 and G6. Geological type G1 and G6 have both Outliers while geological type G1 and G4 both have outliers and extreme values.

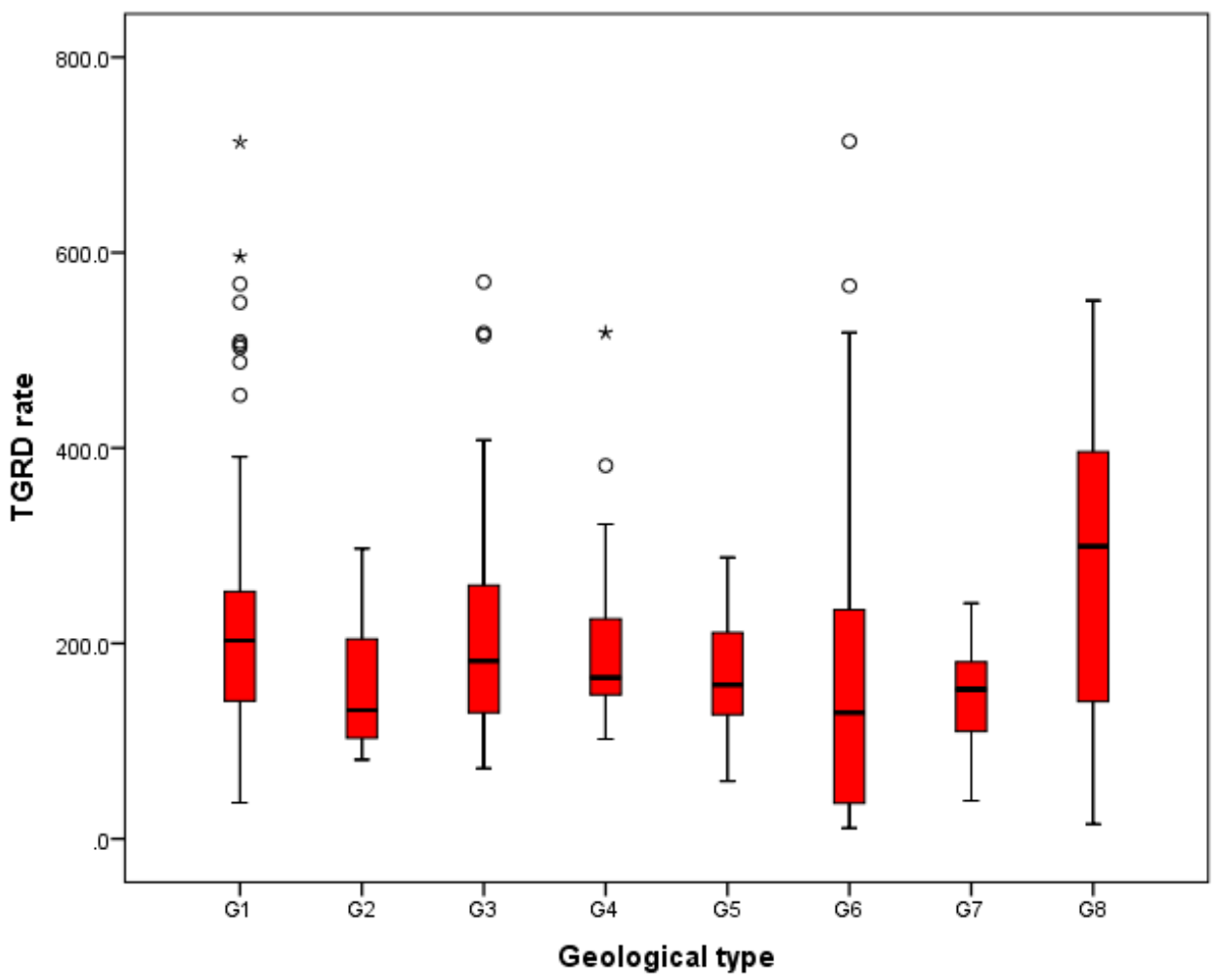

Figure 4. Box plotting for the distribution of TGRD rate for each geological formation.

To examine the influence of geology on dose rate, statistical comparison method was run on the data sets for all the geological formations. This method compared mean values of dependant variables (TGRD rate) between different independent groups (geological types).

One way analysis of variance (ANOVA) was run on the dose rate data for all the geological formations to observe if there is significant difference among the
TGRD mean values for the various geological types of the area. This was based on hypothesis testing approach proposed as null hypothesis and alternate hypothesis which are stated as follows:

Null hypothesis $\left(\mathrm{H}_{0}\right)$ : Mean values of TGRD for the geological types are the same.

Alternate hypothesis $\left(\mathrm{H}_{\mathrm{a}}\right)$ : at least one pair of geological group have their mean values differ.

Therefore, ANOVA statistics was conducted to test the hypothesis and the results is presented in Table 2.

Table 2: ANOVA results of TGRD rate and geological formations

\begin{tabular}{lrrrrr}
\hline Geological type & Sum of Squares & df & Mean Square & F & Sig. \\
& & & & & \\
\hline Between Groups & 435471 & 8 & 62210 & 3.984 & .000 \\
Within Groups & 3700946 & 237 & 15616 & & \\
Total & 4136417 & 244 & & & \\
\hline
\end{tabular}


At degrees of freedom $(8,237)$ and critical value $(0.05)$, the significance value $(0.000)$ is less than the critical value which means the rejection of the null hypothesis. Therefore, the result indicates that there is statistically significant difference among the means TGRD rate for the various geological types of the area. Thus, it may be concluded that with $95 \%$ confidence, the geological types of Jos Plateau have influence on the TGRD rates.
Waller-Duncan post hock test was run to confirm where the differences occurred between the geological types or which geological type actually differs. It is usuallyused whenever a significant difference between three or more group means has been revealed by an analysis of variance (ANOVA) as shown in Table 2 . The results of post hoc homogeneity subset tests is presented in Table 3.

Table 4.3: Homogeneity subset test on GRD rate for the geological formations.

\begin{tabular}{|c|c|c|c|c|}
\hline \multirow[t]{2}{*}{ Geological Formation } & \multirow[t]{2}{*}{$\mathbf{N}$} & \multicolumn{3}{|c|}{ Homogeneous subset of $=0.05$} \\
\hline & & 1 & 2 & 3 \\
\hline G7 & 21 & 145 & & \\
\hline G2 & 24 & 155 & 155 & \\
\hline G5 & 22 & 166 & 166 & \\
\hline G6 & 39 & 171 & 171 & \\
\hline G3 & 19 & 206. & 206 & 206 \\
\hline G1 & 39 & 220 & 220 & 220 \\
\hline G8 & 61 & & 239 & 239 \\
\hline G4 & 20 & & & 288 \\
\hline
\end{tabular}

The results indicate that the mean value of G4 significantly differ from the mean values of Geological type G2, G5 and G6, also geological type G8 clearly differ from that of G7. Geological type G8 differs by its mean value from G2, G5 and G7.The SPSS output for the estimated marginal means plot of TGRD between the geological formations is given in Figure 4. The figure indicatesa clear margin between the means of TGRD rate for all the geological types. For instance, the widest margin is between G7 and G8; their mean values distinctly differ.

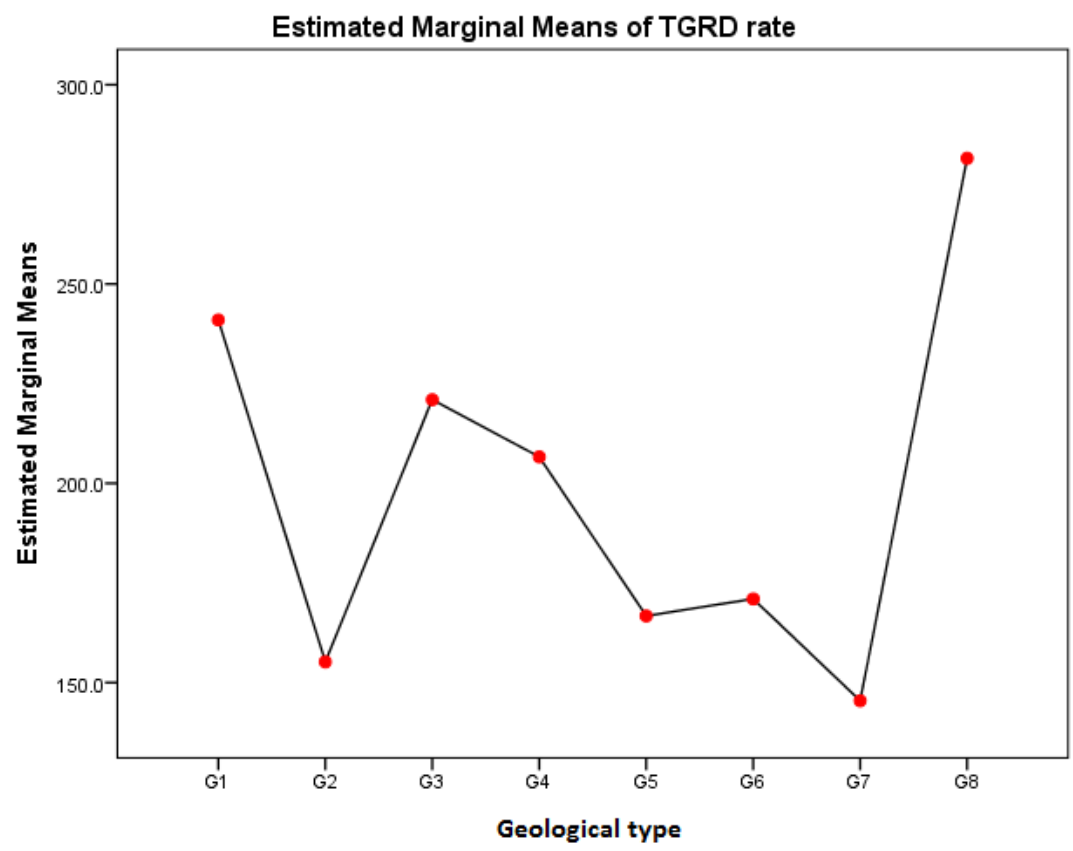

Figure 5: Marginal means plot of TGRD rate for geological types.

Annual effective dose (AED) for the population was estimated using the conversion coefficient (0.7 Sv $\mathrm{Gy}^{-1}$ ) from absorbed dose in air to effective dose received by adults(Ramli, Sahrone, \& Wagiran, 2005; UNSCEAR, 2000) and 0.2 a occupancy factor for outdoor. This was estimated using equation 1 (Sanusi et al., 2014).
The was estimated to be $0.25 \mathrm{mSv}^{-1}$, which is four fold the world average value of $0.07 \mathrm{mSv} \mathrm{y}^{-1}$ (UNSCEAR, 2008) but is below the global permissible limit of $1 \mathrm{mSv}^{-1}$ reported by (ICRP, 2000) and therefore is considered normal from the radiological protection point of view.

Collective effective dose for the general public was -estimated as follows:

Collective effective dose $(S C)=A E D \times N(P)$ 
where $N(P)$ is total population of the study area. Collective effective dose is estimated to be $1.20 \times 10^{2}$ man Sv $\mathrm{y}^{-1}$.

The digitized isodose map for the distribution of exposure rate due to terrestrial gamma radiation was plotted using ArcGIS software as shown in Figure 7. The areas of elevated TGRD rates can be observed in areas around Barkin Ladi, Jos south and Jos north. Younger granites and basement complex predominantly underlie these areas.

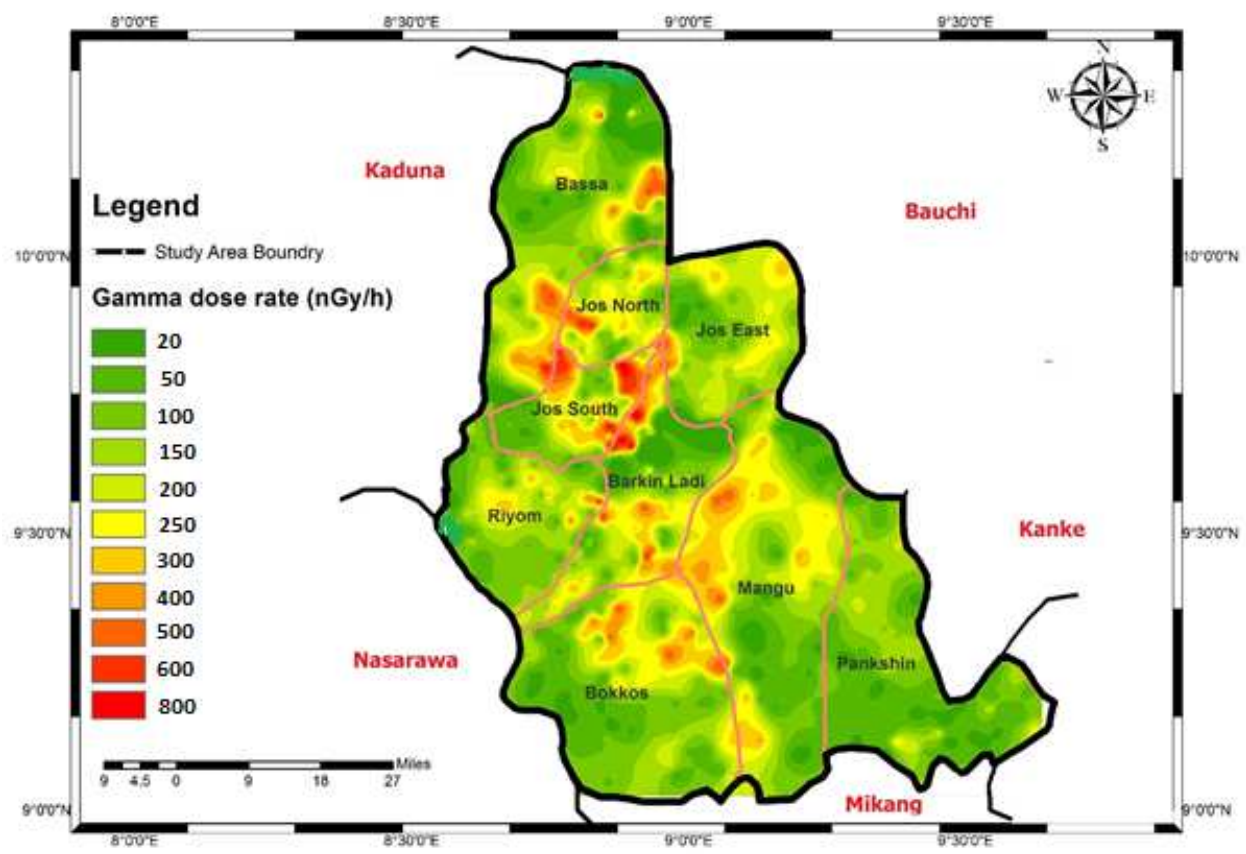

Figure 7. Isodose map for TGRD rate.

\section{CONCLUSION}

The current data support a strong relationship between terrestrial gamma radiation dose rates and the underlying geological types of a location. The results provide means of predicting background terrestrial gamma radiation dose rates based on geological types and assessment of natural radiation dose to the population of Jos Plateau. The average terrestrial gamma radiation dose rate for this study is $204 \mathrm{nGy} \mathrm{h}^{-1}$, which is approximately three fold the world average. The average annual effective dose to individuals staying outdoors and collective dose for the general public are estimated at $0.25 \mathrm{mSv}^{-1}$ and $1.20 \times 10^{2}$ man Sv $y^{-1}$, respectively.

Elevated TGRD rates were found in some areas of Jos Plateau, especially around Barkin Ladi, Jos north and

\section{REFERENCES}

Falconer, J. D. (1921). The geology of the plateau tin fields. authority of the Nigerian government [Waterlow \& Sons, Limited].

Furukawa, M. (1993). Natural radiation level in Japan Islands. Journal of geography, 102:868-877.

Furukawa, M., \& Shingaki, R. (2012). Terrestrial gamma radiation dose rate in Japan estimated before the 2011 Great East Japan Earthquake. Radiat Emerg Med, 1, 11-16.

ICRP. (2000). "Protection of the Public in Situations of Prolonged Radiation Exposure (ICRP
Jos South local government areas. Formations of igneous rocks origin underlie these areas. The highest TGRD rate $82.06 \mathrm{R} \mathrm{h}^{-1}\left(714 \mathrm{nGy} \mathrm{h}^{-1}\right)$ was measured in Barkin Ladi. An individual leaving in such area is expected to receive effective dose annually of 0.88 $\mathrm{mSv} \mathrm{y}^{-1}$ though is less than the global acceptable limit of $1.0 \mathrm{mSv} \mathrm{y}^{-1}$.

\section{ACKNOWLEDGEMENTS}

This work is conducted with financial support from the Ministry of Science, Technology and Innovation (MOSTI), Malaysia (Grant No. R.J130000.7926.4S109). The authors also wish to Thank Universiti Teknologi Malaysia for providing various facilities and opportunities.

\section{CONFLICT OF INTEREST}

The authors declare no conflict of interest.

Publication 82)," International Commission on Radiological Protection (ICRP), Pergamon Press, Oxford, 2000.

Jibiri, N. (2001). Assessment of health risk levels associated with terrestrial gamma radiation dose rates in Nigeria. Environment International, 2Л1), 21-26.

Knoll, G. F. (2010). Radiation detection and measurement: John Wiley \& Sons.

Lai, K., Hu, S., Minato, S., Kodaira, K., \& Tan, K. (1999). Terrestrial gamma ray dose rates of 
Brunei Darussalam. Applied Radiation and Isotopes, 50(3), 599-608.

Ludlum Measurement. (1993). Instruction Manual of Ludlum Model 19 Micro R Meter. Ludlum Measurements, Inc, Sweetwater Texas.

Macleod, W. N., Turner, D. C., \& Wright, E. P. (1971). The Geology of Jos Plateau. Bulletin Geological Survey of Nigeria. 32 Vol1., pp. 12-47 pp.

NPC. (2006). National population Commission (NPC):. Provisional of 2006 Census Results.

Olowolafe, A. E. (2008). Land use effects on the properties of an Alfisol on the Jos Plateau, Nigeria. GeoJournal, 71(2-3), 83-91.

Ramli, A. T., Sahrone, S., \& Wagiran, H. (2005). Terrestrial gamma radiation dose study to determine the baseline for environmental radiological health practices in Melaka state, Malaysia. Journal of Radiological Protection, 25(4), 435.

Ravisankar, R., Chandramohan, J., Chandrasekaran, A., Jebakumar, J. P. P., Vijayalakshmi, I., Vijayagopal, P., \& Venkatraman, B. (2015). Assessments of radioactivity concentration of natural radionuclides and radiological hazard indices in sediment samples from the East coast of Tamilnadu, India with statistical approach. Marine pollution bulletin, 971), 419-430.

Sanusi, M., Ramli, A., Gabdo, H., Garba, N., Heryanshah, A., Wagiran, H., \& Said, M. (2014). Isodose mapping of terrestrial gamma radiation dose rate of Selangor state, Kuala Lumpur and Putrajaya, Malaysia. Journal of Environmental Radioactivity, 135, 67-74.

Tzortzis, M., Svoukis, E., \& Tsertos, H. (2004). A comprehensive study of natural gamma radioactivity levels and associated dose rates from surface soils in Cyprus. Radiation Protection Dosimetry, 109(3), 217-224.

UNSCEAR. (2000). Sources and effects of ionizing radiation. Retrieved from United Nations Scientific Committee on the Effects of Atomic Radiation. Report to the General Assembly with scientific annexes.:

UNSCEAR. (2008). Sources and effects of ionizing radiation. United Nations Scientific Committee on the Effects of Atomic Radiation, New York. 